\title{
Study on Surface-Enhanced Raman Scattering Substrate Based on Titanium Oxide Nanorods Coated with Gold Nanoparticles
}

\author{
Xiaodong Wang, ${ }^{1}$ Xiulan Cheng $\mathbb{D}^{2},{ }^{2}$ Xufeng Yu, ${ }^{1}$ and Xueling Quan ${ }^{2}$ \\ ${ }^{1}$ School of Microelectronics, Shanghai Jiao Tong University, 800 Dongchuan Road, Shanghai 200240, China \\ ${ }^{2}$ Center for Advanced Electric Materials and Devices, Shanghai Jiao Tong University, 800 Dongchuan Road, \\ Shanghai 200240, China \\ Correspondence should be addressed to Xiulan Cheng; xlcheng@sjtu.edu.cn
}

Received 14 August 2017; Accepted 28 January 2018; Published 1 April 2018

Academic Editor: Paresh Chandra Ray

Copyright (c) 2018 Xiaodong Wang et al. This is an open access article distributed under the Creative Commons Attribution License, which permits unrestricted use, distribution, and reproduction in any medium, provided the original work is properly cited.

\begin{abstract}
A 3D surface-enhanced Raman scattering (SERS) substrate based on titanium oxide nanorods ( $\mathrm{TiO}_{x}$-NRs) coated with gold nanoparticles (Au-NPs) was fabricated by a simple hydrothermal, no-template process. The nanostructure of $\mathrm{TiO}_{x}-\mathrm{NRs}$ influenced by the concentrations of hydrochloric $(\mathrm{HCl})$ acid and sodium chloride $(\mathrm{NaCl})$ was studied in detail. The substrate showed the strongest Raman enhancement, when the diameters of Au-NPs were around $40 \mathrm{~nm}$ and the gaps of Au-NPs were in the range of $5 \mathrm{~nm}$ to $10 \mathrm{~nm}$. The surface electric field of our substrate was examined by finite-different time-domain (FDTD) solutions. Rhodamine 6G (R6G) was chosen as the probe molecule to study the SERS performance of the substrates. The Raman signal of $10^{-10} \mathrm{M}$ R6G was detected clearly by the substrate with the enhancement factor of $2.64 \times 10^{8}$. All relative standard deviation (RSD) values of the major peaks for R6G were within the scope of $10.4 \%$ to $16.7 \%$. The substrate could work efficiently even after immersed in water for one month.
\end{abstract}

\section{Introduction}

SERS substrates have drawn tons of attention in the fields such as analytical chemistry [1], environment protection [2], medical remedy [3], biology detection [4], and so on, for its high sensitivity, quick response, and universal properties to most organic molecules. Research on the SERS substrates combined with $3 \mathrm{D}$ semiconductor nanostructure and noble metal nanoparticles $[5,6]$ is currently a hot research area due to their high local field enhancement (LFE) [7]. A series of semiconductor nanostructures coated by noble metal has been made, like $\mathrm{Au}-\mathrm{TiO}_{2}$ [8], $\mathrm{Ag}-\mathrm{TiO}_{2}$ [9], Ag-GaN [10], $\mathrm{Au}-$ $\mathrm{ZnO}$ [11], Ag-ZnO [12], Ag-Si [13], and so on.

Surface plasmon resonance $[14,15]$ and charge transfer mechanism $[16,17]$ are considered as the major contributions in the noble metal-semiconductor SERS system. In the theory of surface plasmon resonance, when exciting laser interacts with the electrons in the metal conduction band, there would be a strong electric field in the metal surface. The high electric field would interact with the absorbed molecule. In this condition, Raman signal is sharply enhanced at the junction between the nanoparticles [18], atomic clusters [19], or sharp edges [20], which are called hotspots. Therefore, a mass of uniformly distributed hotspots is important for high-sensitive SERS substrates. Meanwhile, 3D nanostructures (e.g., nanowire, nanoshell, and nanorods) could provide sufficient hotspots forming locations because of its large specific surface area [21,22].

Based on the charge transfer mechanism, when the molecules bond to semiconductor appropriately [17], charge would transfer from semiconductor to absorbed molecules under exciting laser, which could enhance the Raman signal obviously. Semiconductor with lower bandgap would realize this mechanism easier. In consideration of the dramatic SERS enhancement from semiconductor nanostructure, semiconductors $\mathrm{TiO}_{2}, \mathrm{ZnO}$, and $\mathrm{Si}$ are always chosen as the substrate material [23-25].

Compared with conventional $\mathrm{Si}$ or $\mathrm{ZnO}, \mathrm{TiO}_{2}$ is widely used in photocatalytic degradation and polluted water purification [26] due to its perfect chemical, thermal stability, better biocompatibility, and low cost [27]. Hydrothermal synthesis $[28,29]$ rather than anodic oxidation [30] and 
template-based synthesis [31] are used to fabricate $\mathrm{TiO}_{x}$ for its simple process, high yield, and low cost. The lattice structure of rutile $\mathrm{TiO}_{2}$ is the same as that of fluorine-doped $\mathrm{SnO}_{2}$ (FTO), and the lattice mismatch is just about 2\% [32], so FTO glass was selected as the substrate to improve the nucleation and growth of hydrothermal-synthesized $\mathrm{TiO}_{2}$ nanorods.

$\mathrm{Au}$ and Ag are widely used in SERS substrates due to their perfect surface plasmon resonance mechanism [3335]. Au is more suitable to make recyclable SERS substrates for its chemical stability.

In this work, a kind of highly ordered $\mathrm{TiO}_{x}-\mathrm{NR}(x<2)$ SERS substrate coated with Au-NPs was demonstrated experimentally. A SERS substrate stacked by disordered $\mathrm{TiO}_{2}$ nanowires supporting gold nanocrystals had been proposed in our previous research work firstly [36]. $\mathrm{TiO}_{x}(x<2)$ SERS substrate would realize charge transfer mechanism easier than $\mathrm{TiO}_{2}$. Meanwhile, compared with $\mathrm{TiO}_{2}$ powder SERS substrate [9], ordered $\mathrm{TiO}_{x}-\mathrm{NR}$ based on FTO glass SERS substrate is more suitable in recycling application. The $\mathrm{pH}$ and chloridion concentration $\left(\left[\mathrm{Cl}^{-}\right]\right)$in our reaction were optimized to obtain better morphology of $\mathrm{TiO}_{x}-\mathrm{NRs}$. We also changed sodium citrate $\left(\mathrm{Na}_{3} \mathrm{Ct}\right) /$ chloroauric acid $\left(\mathrm{HAuCl}_{4}\right)$ concentration ratio to adjust size and density of Au-NPs. R6G was chosen as the probe molecule for its strong fluorescence effect and large Raman scattering cross section.

\section{Materials and Experimental}

2.1. Materials. (3-Aminopropyl)triethoxysilane (APTES, 98\%) was purchased from Aladdin. Titanium isopropoxide (TTIP, Ti 16.6-16.9\%), chloroauric acid $\left(\mathrm{HAuCl}_{4}\right.$, $\mathrm{Au} \geq 47.8 \%$ ), rhodamine 6G (95\%), concentrated sulfuric acid (AR, 95.0\%-98.0\% by weight), hydrogen peroxide (AR, $30 \%$ ), acetone (AR), ethanol (AR), hydrochloric acid (AR, $36.5 \%-38 \%$ by weight), sodium chloride (AR), and sodium citrate $\left(\mathrm{Na}_{3} \mathrm{Ct}, \mathrm{AR}\right)$ were purchased from Sinopharm. Fluorine-doped tin oxide (FTO) glass (FTO-P001, <10 $\Omega /$ sq) was purchased from Kaivo Optoelectronic Technology Co.

2.2. Instrument. Au-NPs were deposited by the ion sputtering equipment (HTCY Technology Co. JS-1600) or by the citrate reduction method with the help of the thermostat magnetism stirrer (Jintan Jiangsu Xinbao 90-2). Morphologies of the samples were characterized with the field emission scanning electron microscope (FESEM, Zeiss Ultra Plus). Annealing was processed by high-temperature electric oven (Shanghai Xunbo $\mathrm{SX}_{2}$ ). The phase of titanium oxide was analyzed by X-ray diffraction (XRD, Bruker D8 ADVANCE). Raman spectra of R6G were measured with the dispersive Raman microscope (Horiba HR Evolution). Ultraviolet light condition was realized by an ultraviolet analyzer (Shanghai Jihui ZF-7).

2.3. Hydrothermal Synthesis of $\mathrm{TiO}_{x}$-NRs. Before experiment, a piece of FTO glass was cleaned in the mixture of concentrated piranha solution $\left(\mathrm{H}_{2} \mathrm{SO}_{4}: \mathrm{H}_{2} \mathrm{O}_{2}=3: 1\right)$ at $80^{\circ} \mathrm{C}$ for
$10 \mathrm{~min}$. Piranha solution should be operated in ventilated hood, and the operator should wear protection suit, rubber gloves, and goggles. Then, the FTO glass was washed by deionized (DI) water and dried with nitrogen.

An experiment was designed to explore the effect of $\mathrm{pH}$ value and concentration of $\left[\mathrm{Cl}^{-}\right]$on the orientation growth of $\mathrm{TiO}_{x}$-NRs. Firstly, $0.7 \mathrm{M} \mathrm{NaCl}$ and $0.042 \mathrm{M}$ TTIP $\left(\mathrm{C}_{12} \mathrm{H}_{28} \mathrm{O}_{4} \mathrm{Ti}\right)$ were added into the diluted $\mathrm{HCl}$ solution with different concentrations, for example, $7.0 \mathrm{M}, 6.0 \mathrm{M}, 5.0 \mathrm{M}$ and $4.0 \mathrm{M}$. Then, the concentration of $\left[\mathrm{Cl}^{-}\right]$can be further tuned by adding $\mathrm{NaCl}$ salt, for example, $0 \mathrm{M}, 0.55 \mathrm{M}, 0.7 \mathrm{M}$, and $0.85 \mathrm{M}$. Thereafter, the solution was transferred into a sealed Teflon hydrothermal reaction vessel. The FTO glass was placed at an angle against the inner wall of vessel with the conductive side facing down. The vessel was sealed and put in oven at $150^{\circ} \mathrm{C}$ for $18 \mathrm{~h}$. After that, the vessel was cooled to room temperature naturally. The sample was taken out and rinsed with deionized water for three times to wash out the residual reactant. Finally, the crystallization of $\mathrm{TiO}_{x}-\mathrm{NRs}$ film was carried out by annealing at $500^{\circ} \mathrm{C}$ for $30 \mathrm{~min}$.

2.4. Decoration of Gold Nanoparticles. Two different deposition methods for Au-NPs attaching on $\mathrm{TiO}_{x}$-NRs were used in this work. One was ion sputtering with ion current $20 \mathrm{~mA}$ for $30 \mathrm{~s}$. Another was the citrate reduction method. In citrate reduction, the density and size of $\mathrm{Au}-\mathrm{NPs}$ were varied by changing the initial $\mathrm{HAuCl}_{4}$ concentrations. $\mathrm{TiO}_{x}-\mathrm{NRs}$ substrate was amino-modified in the fresh-made amination solution ( $40 \mu \mathrm{L}$ of APTES, $0.5 \mathrm{~mL}$ of DI water, and $0.5 \mathrm{~mL}$ of ethanol) for $20 \mathrm{~min}$ firstly. Thereafter, the samples were dried at $60^{\circ} \mathrm{C}$ for $10 \mathrm{~min}$ and then cleaned in ultrasonic cleaning with deionized water for $1 \mathrm{~min}$. After that, the sample was put in Au-NPs citrate reduction solution, which consisted of $1.5 \times 10^{-2} \mathrm{M} \mathrm{Na}{ }_{3} \mathrm{Ct}$ and special concentration $\mathrm{HAuCl}_{4}$ (e.g., $1.0 \times 10^{-4} \mathrm{M}, 2.0 \times 10^{-4} \mathrm{M}, 3.0 \times 10^{-4} \mathrm{M}$, and $\left.4.0 \times 10^{-4} \mathrm{M}\right)$. The reactant should be kept on boiling and stirring condition for $10 \mathrm{~min}$. When finishing, the solution was cooled to room temperature naturally. At last, the sample was taken out and rinsed with DI water.

2.5. XRD Detection. The crystallization of sample was detected by XRD with the following parameters: $0.154056 \mathrm{~nm}$ of wavelength of X-ray, $40 \mathrm{kV}$ of working voltage, $30 \mathrm{~mA}$ of working current, $0.2^{\circ}$ of scanning step, and $0 \sim 90^{\circ}$ of scanning range.

2.6. Measurement of Raman Spectrum. All Raman spectra in this paper were measured with dispersive Raman microscope of Horiba HP Evolution. The wavelength of excitation laser was set as $532 \mathrm{~nm}$, the power was $0.2 \mathrm{~mW}$, the diameter of the focused laser beam was $1 \mu \mathrm{m}$, and accumulation time was $10 \mathrm{~s}$. Before measurement, the samples were dyed by R6G solution for half an hour. Then, the sample was taken out and dried at room temperature naturally in dark condition. Three different places were detected for each sample. 


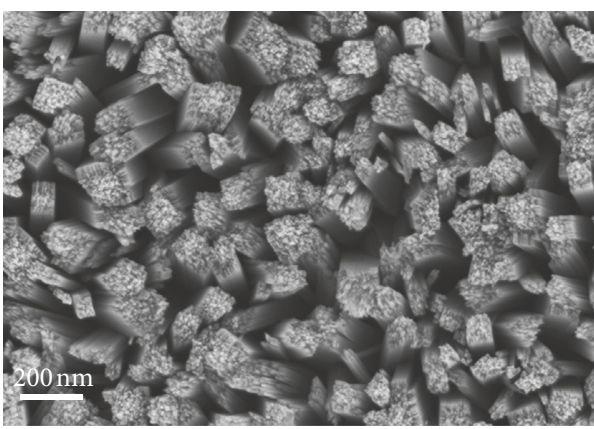

(a)

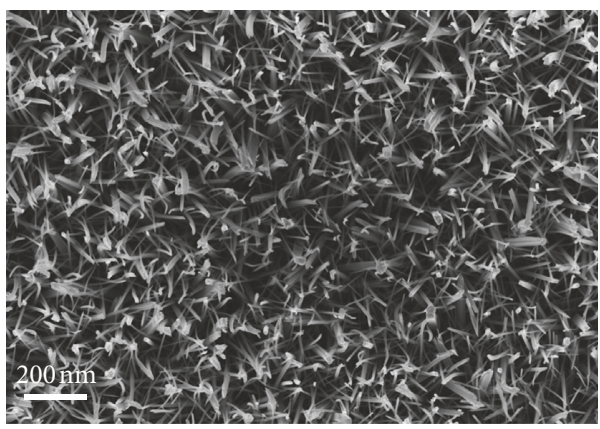

(c)

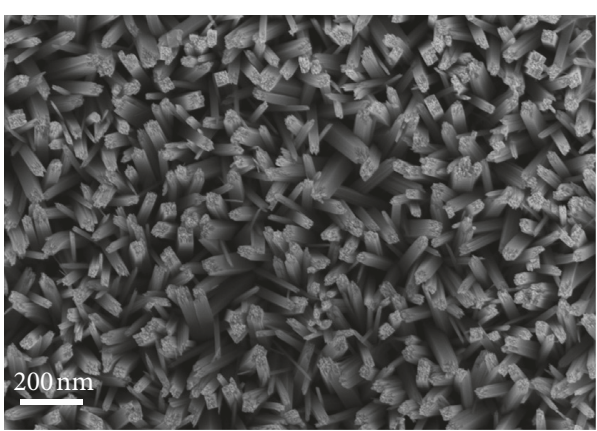

(b)

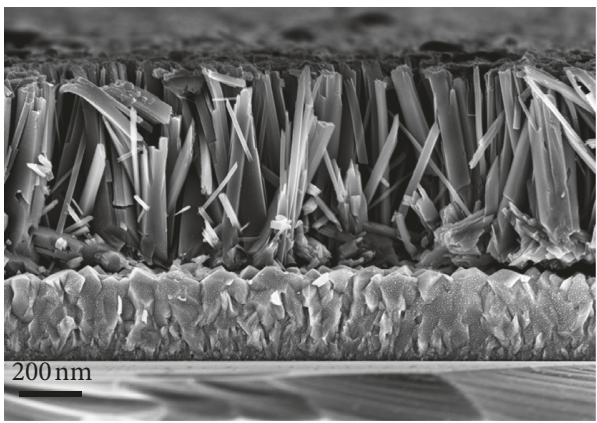

(d)

Figure 1: FESEM images of $\mathrm{TiO}_{x}$-NRs, which were made by different concentrations of $\mathrm{HCl}$ : (a) $4 \mathrm{M}$, (b) $5 \mathrm{M}$, (c) $6 \mathrm{M}$, and (d) the cross section of (b).

\section{Results and Discussion}

3.1. Synthesis of $\mathrm{TiO}_{x}$-NRs. After hydrothermal synthesis reaction, a white thin film of $\mathrm{TiO}_{x}$-NRs was coated on the conductive FTO glass surface. The effect of $\mathrm{pH}$ value on the growth of $\mathrm{TiO}_{x}$-NRs is shown in Figure 1. It can be found that the $\mathrm{TiO}_{x}$-NRs are cuboid and nearly vertical to the substrate with a small angle ranging from 0 to 15 degrees. The top surface of nanorods is in sidestep shape composed of dozens of nanowires, whereas sidewalls are quite flat. The length of nanorods is about $2 \mu \mathrm{m}$. Diameters of nanorods decrease with the increase in concentration of $\mathrm{HCl}$.

For the low $\mathrm{HCl}$ concentration (e.g., $4 \mathrm{M}$ shown in Figure 1(a)), the titanium resultants grow as nanorods with small intervals, some even combine together and form a huge one. For the high concentration (e.g., $6 \mathrm{M}$ shown in Figure 1(c)), the titanium resultants are too small to gather in block mass. When the $\mathrm{HCl}$ concentration is $5 \mathrm{M}$, the diameter and intervals of $\mathrm{TiO}_{x}-\mathrm{NRs}$ are around $200 \mathrm{~nm}$ and $100 \mathrm{~nm}$, respectively (shown in Figure 1(b)), which is suitable for AuNPs deposition.

This result can be explained by the fact that high concentration of $\mathrm{HCl}$ (low $\mathrm{pH}$ ) can suppress the rapid hydrolysis of TTIP in aqueous solution [37]. The morphology of $\mathrm{TiO}_{x}$ would change from nanorods to nanowires. When the concentration of $\mathrm{HCl}$ reaches $7 \mathrm{M}$, there would be no $\mathrm{TiO}_{x}$-NRs.

As for $\left[\mathrm{Cl}^{-}\right], \mathrm{TiO}_{x}-\mathrm{NRs}$ get looser and smaller with the increase in $\left[\mathrm{Cl}^{-}\right]$concentration, as shown in Figure 2. The reason for this phenomenon can be explained by the fact that TTIP precursor would form $\left[\mathrm{Ti}(\mathrm{OH})_{2} \mathrm{Cl}_{x}\left(\mathrm{OH}_{2}\right)_{y}\right]^{n \pm}$ $(x+y=4)$ with the attendance of $\left[\mathrm{Cl}^{-}\right]$. The intermediate products would suppress TTIP precursor hydrolysis [38] and result in smaller $\mathrm{TiO}_{x}$-NRs.

In view of $3 \mathrm{D}$ structure role in SERS substrates, $\mathrm{TiO}_{x^{-}}$ NRs with the largest surface area should be chosen. The samples shown in Figures 1(b) and 1(c) have much larger surface area. We decorated the Au-NPs on the two substrates with $3 \times 10^{-4} \mathrm{M} \mathrm{HAuCl}_{4}$ and $1.5 \times 10^{-2} \mathrm{M} \mathrm{Na}_{3} \mathrm{Ct}$. The Raman spectra of the two samples dyed by $10^{-6} \mathrm{M}$ R6G are shown in Figure 3. The Raman signal on sample synthesized with $5 \mathrm{M}$ $\mathrm{HCl}$ showed much higher Raman enhancement. So the nanorod substrate synthesized with $5 \mathrm{M}$ of $\mathrm{HCl}, 4.2 \times 10^{-2} \mathrm{M}$ of TTIP, and $0.7 \mathrm{M}$ of $\mathrm{NaCl}$ was chosen as the basement in the following experiments.

The XRD spectrum for the optimal $\mathrm{TiO}_{x}$-NRs is shown in Figure 4, in which Au-NPs substrate shows that only one type of titanium oxide $\mathrm{TiO}_{1.04}$ rather than $\mathrm{TiO}_{2}$ is found in our substrate after annealing. The other diffraction peaks mainly come from $\mathrm{SnO}_{2}$ FTO glass substrate. There is hardly a diffraction peak of Au due to its low proportion. According to the work by Gruber and Krautz, the conductivity of $\mathrm{TiO}_{x}$ is changed with $x$. When $1.0 \leq x \leq 1.03, \mathrm{TiO}_{x}$ shows metallic conductivity; when $1.04 \leq x \leq 1.24, \mathrm{TiO}_{x}$ shows semiconductivity [39].

Based on the charge transfer mechanism between semiconductor and absorbed molecules reported by Yang et al. [17], the energy is difficult to excite electrons crossing the bandgap of $\mathrm{TiO}_{2}(3.4 \mathrm{eV})$ or the energy gap between LUMO (lowest unoccupied molecular orbital) and HOMO 


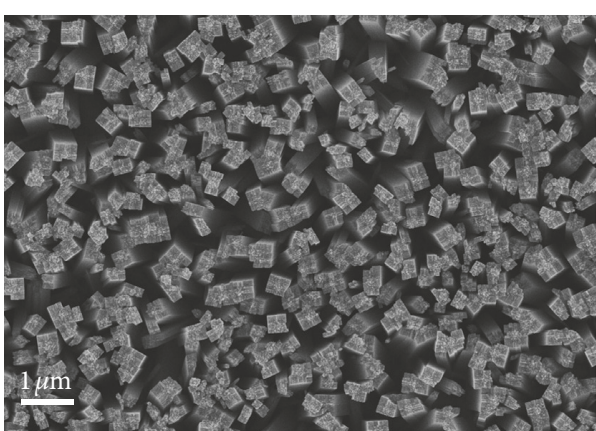

(a)

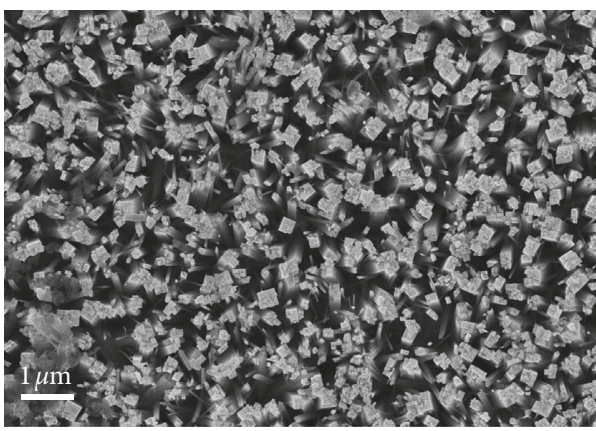

(c)

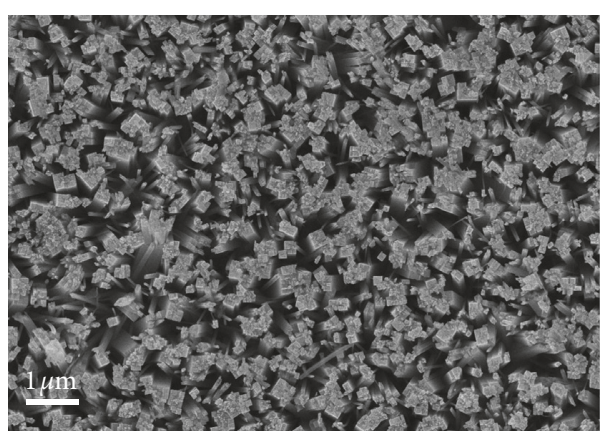

(b)

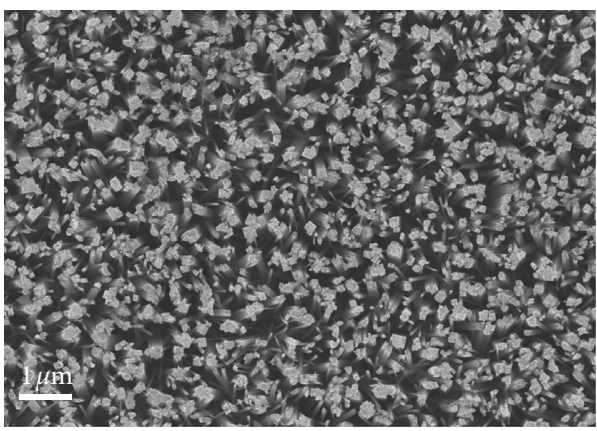

(d)

Figure 2: FESEM images of nanorods synthesized with different $\mathrm{NaCl}$ concentrations: (a) $0 \mathrm{M}$, (b) $0.55 \mathrm{M}$, (c) $0.7 \mathrm{M}$, and (d) $0.85 \mathrm{M}$.

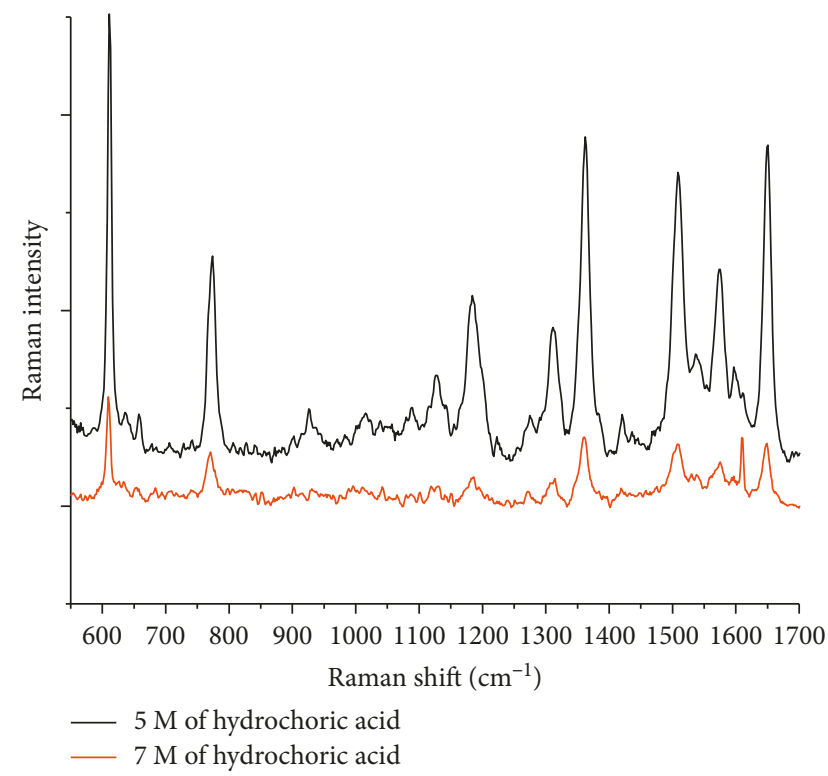

FIGURE 3: Raman spectra for samples b and c dyed by $10^{-6} \mathrm{M}$ R6G.

(highest occupied molecular orbital) for absorbed molecules under $514.5 \mathrm{~nm}(2.4 \mathrm{eV})$ laser illumination. So charge transfer of $\mathrm{TiO}_{2}$ could only be realized by electrons excited from VB (valence band) to surface state energy levels firstly and then transfer to LUMO. Mott and Friedman reported that the bandgap of $\mathrm{TiO}_{1.5}$ is of order $\sim 1 \mathrm{eV}$ [40]. This can be explained by the fact that there is less $\mathrm{O}$ atom vacancy in $\mathrm{TiO}_{x}(x<2)$ with lower $x$. Therefore, $\mathrm{TiO}_{1.04}$ with less than $1.0 \mathrm{eV}$ bandgap is helpful in charge transferring

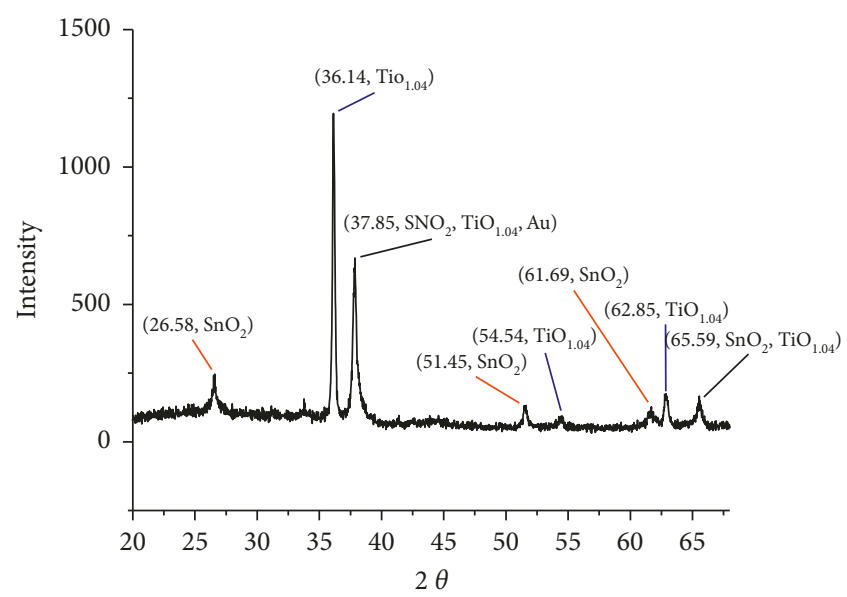

Figure 4: X-ray diffraction spectrum of $\mathrm{TiO}_{x}$ nanorod after annealing synthesized on FTO glass.

across bandgap to LUMO easily under $532 \mathrm{~nm}$ laser $(2.33 \mathrm{eV})$ illumination and can be considered as a kind of SERS substrate with high-detection sensitivity (Figure 5).

3.2. Decoration of Au-NPs. The morphology of Au-NPs attached by two methods has shown great differences. The $\mathrm{Au}-\mathrm{NPs}$ were decorated by physical sputtering mainly gathered on the top surface of nanorods, as shown in Figure 6(a). The nanoparticles are spheroidicity with size about $20 \mathrm{~nm}$. There is a shortage of Au-NPs to form hotspots, and the gathering phenomenon would also prevent electromagnetism enhancement between Au-NPs. 


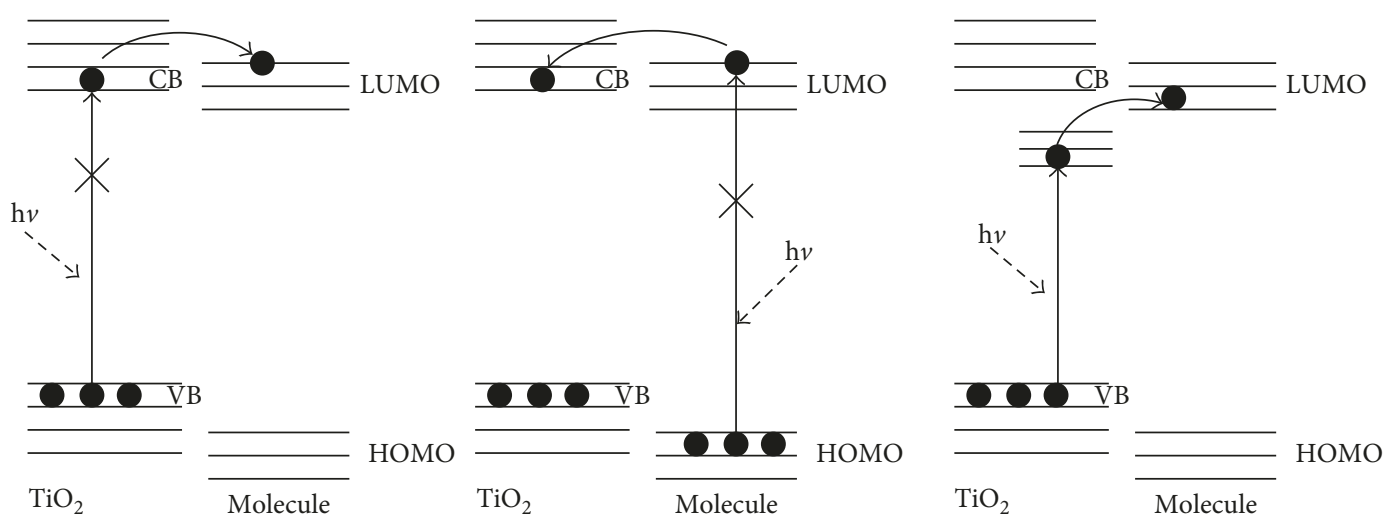

Figure 5: Charge transfer mechanism model between absorbed molecule and $\mathrm{TiO}_{2}$. Schematic diagram obtained from the work by Yang et al. [17].

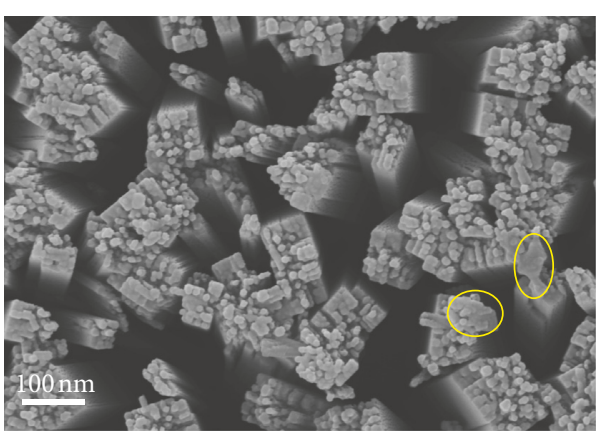

(a)

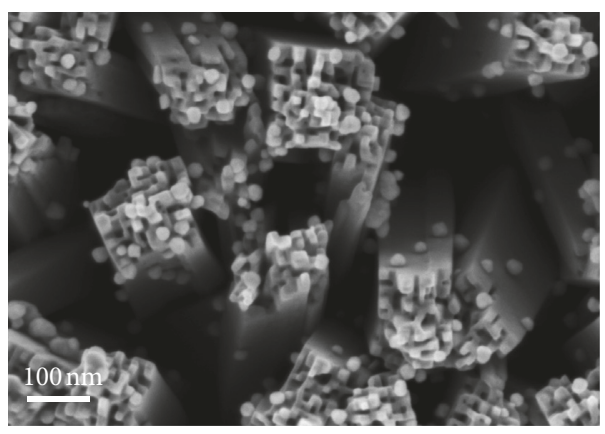

(c)

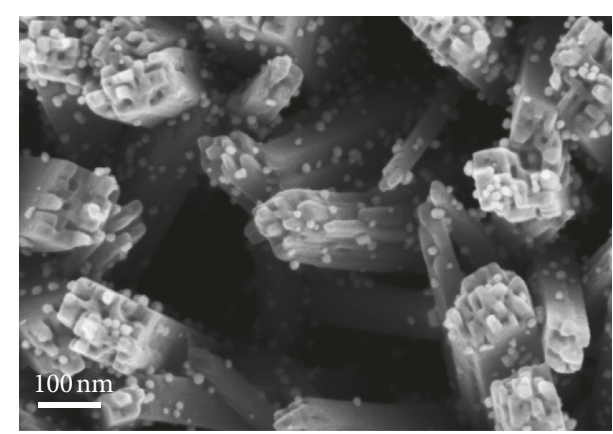

(b)

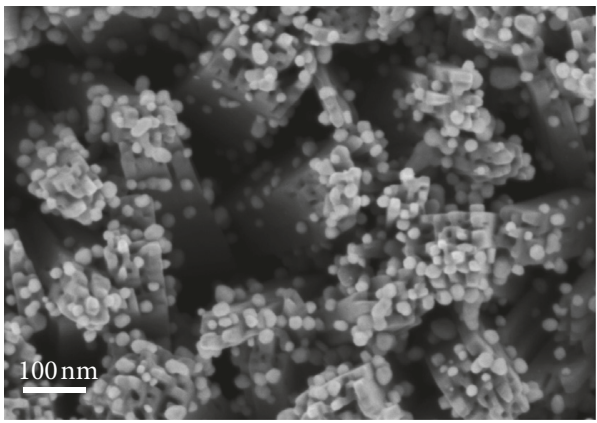

(d)

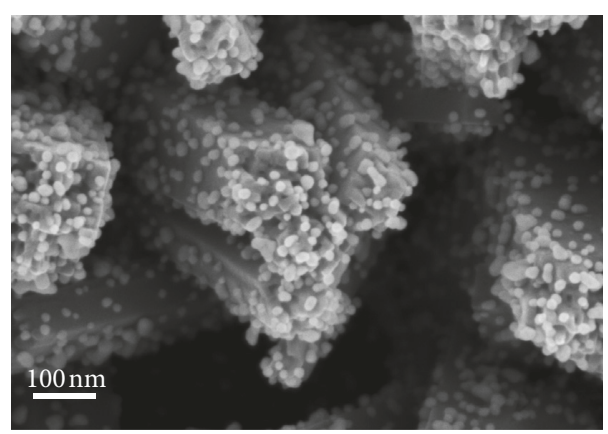

(e)

FIGURE 6: (a) FESEM images of Au-NPs decorated by physical sputtering method. FESEM images of Au-NPs decorated on $\mathrm{TiO}_{x}$-NRs film with (b) $1.0 \times 10^{-4} \mathrm{M}$, (c) $2.0 \times 10^{-4} \mathrm{M}$, (d) $3.0 \times 10^{-4} \mathrm{M}$, and (e) $4.0 \times 10^{-4} \mathrm{M} \mathrm{HAuCl}_{4}$. 


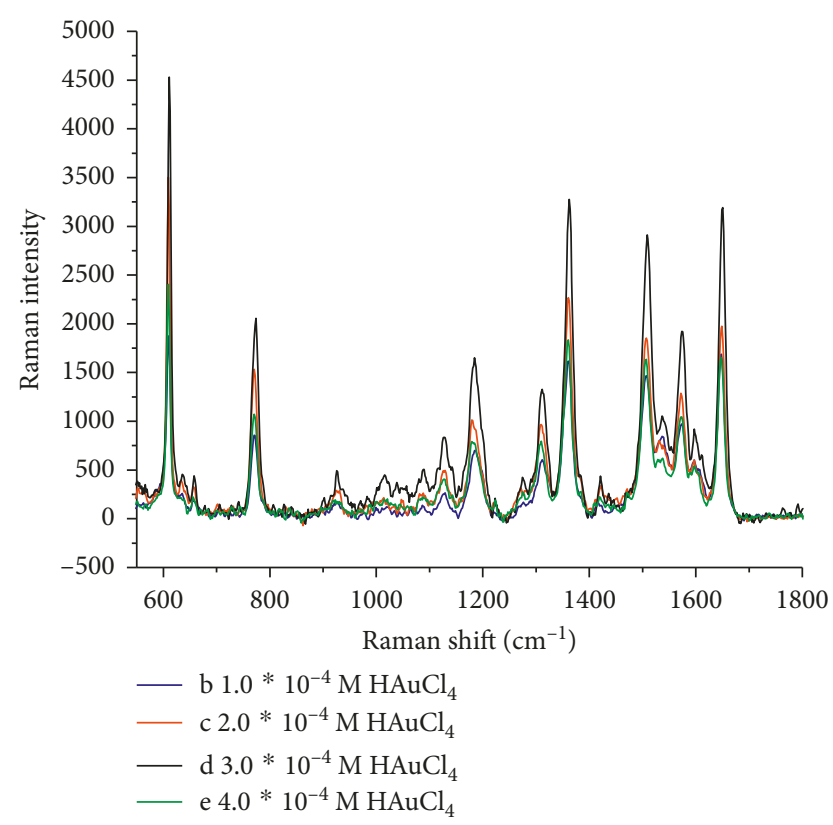

FIGURE 7: Raman spectra of the substrates reduced with different doses of $\mathrm{HAuCl}_{4}$.

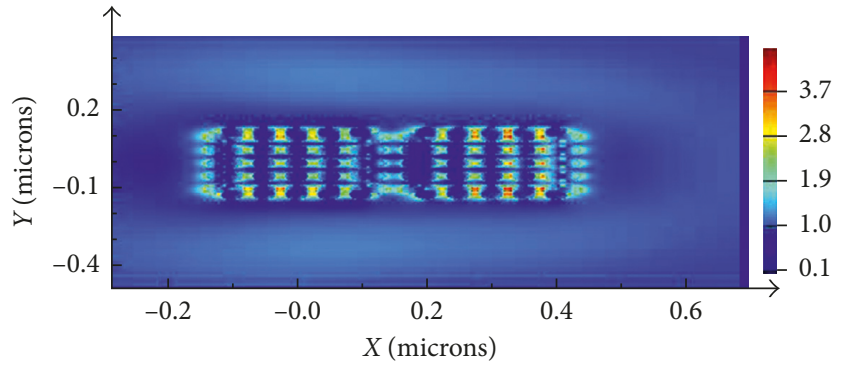

(a)

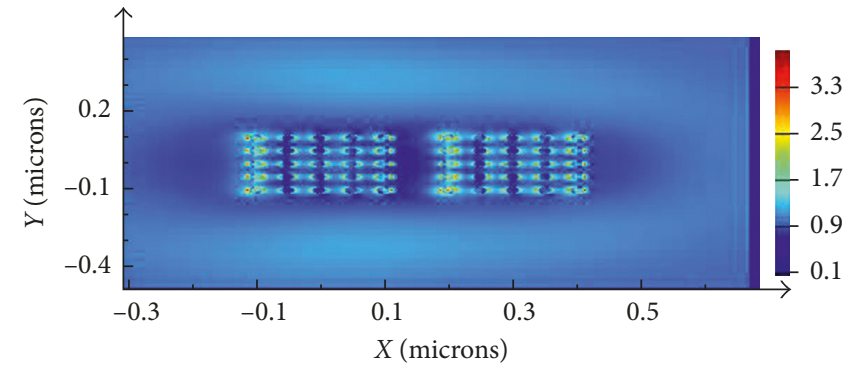

(b)

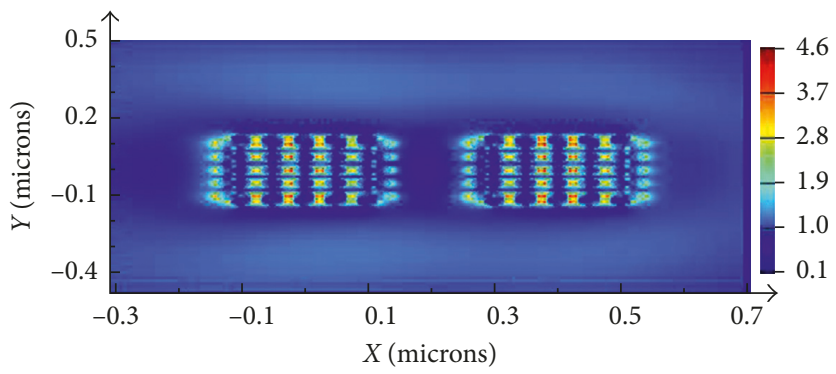

(c)

FIGURE 8: Simulation results of electric field distribution of SERS substrates we have made. The size of all TiO ${ }_{x}-\mathrm{NRs}$ is $200 \mathrm{~nm}$; periods of AuNPs are $50 \mathrm{~nm}$. Diameters of Au-NPs and gap between $\mathrm{TiO}_{x}-\mathrm{NRs}$ are different: (a) $40 \mathrm{~nm}$ and $100 \mathrm{~nm}$, (b) $20 \mathrm{~nm}$ and $100 \mathrm{~nm}$, and (c) $40 \mathrm{~nm}$ and $200 \mathrm{~nm}$.

A large number of Au-NPs attached by chemical reduction methods are uniformly distributed on all surfaces of $\mathrm{TiO}_{x}$-NRs as shown in Figures 6(b)-6(e). Compared with the physical sputtering, this kind of SERS substrate has more hotspots. Four kinds of SERS substrates with $1.0 \times 10^{-4} \mathrm{M}$, $2.0 \times 10^{-4} \mathrm{M}, 3.0 \times 10^{-4} \mathrm{M}$, and $4.0 \times 10^{-4} \mathrm{M} \mathrm{HAuCl}_{4}$ were prepared, respectively. In nucleation-growth process, the size and nucleation rate of $\mathrm{Au}$ increase with the $\mathrm{Na}_{3} \mathrm{Ct} / \mathrm{HAuCl}_{4}$ ratio decrease, when the amount of $\mathrm{HAuCl}_{4}$ is fixed [41]. In our experiment, we changed the $\mathrm{HAuCl}_{4}$ concentration intended to change the size and density of Au-NPs at the same time. As shown in Figures 6(b)-6(e), the density of Au$\mathrm{NPs}$ increases with $\mathrm{HAuCl}_{4}$ concentration. When $\mathrm{HAuCl}_{4}$ concentration was varied from $1.0 \times 10^{-4} \mathrm{M}$ to $3.0 \times 10^{-4} \mathrm{M}$, 
the size and density of Au-NPs increase with the decrease in $\mathrm{Na}_{3} \mathrm{Ct} / \mathrm{HAuCl}_{3}$ ratio. Once, $\mathrm{HAuCl}_{4}$ concentration reaches $4.0 \times 10^{-4} \mathrm{M}$, Au-NPs size decrease. In consideration of the nucleation-growth process, nucleation, aggregation, and intraparticle ripening [41], this phenomenon can be attributed to the excessive nucleuses in the nucleation stage, resulting in $\mathrm{HAuCl}_{4}$ shortage in the aggregation stage. In Figure 6(d), the diameters of Au-NPs are around $40 \mathrm{~nm}$, and the nanogaps between Au-NPs are in the range of $5 \mathrm{~nm}$ to $10 \mathrm{~nm}$. After image analyzing with Image Pro, it shows that total area percentage of Au nanoparticles attaching on the nanorod sidewall surface is about $16 \%$, while that on the top surface is about $12.28 \%$.

3.3. Raman Scattering Measurement. The Raman spectra of $10^{-6} \mathrm{M}$ R6G on four substrates are shown in Figure 7. According to the Raman signal of R6G, sample d shows the highest Raman enhancement. Although sample e has the highest density of Au-NPs, the Raman signal of sample e is lower than samples $\mathrm{c}$ and d. So the density and the size of hotspots should be considered at the same time when making SERS substrates. On the strongest substrate $d$, the diameter and gap of Au-NPs are around $40 \mathrm{~nm}$ and $5 \mathrm{~nm}-10 \mathrm{~nm}$, respectively. The sample $\mathrm{d}$ was considered to be the optimal substrate for further research.

The surface plasmon resonant mechanism was verified by finite-different time-domain solutions in numerical soft Lumerical solutions. According to the results of the substrate we have made, three FDTD simulations were processed. The exciting light was $532 \mathrm{~nm}$, and the light rotated 15 degrees to normal line in accordance with $\mathrm{TiO}_{x}$-NRs-based angle on FTO glass. It was assumed that Au-NPs were uniformly distributed on our substrate. Simulation results are shown in Figure 8. Comparing Figure 8(a) with Figure 8(b), the SERS substrate with $40 \mathrm{~nm}$ Au-NPs had more intensive electric field between Au-NPs than the substrate with $20 \mathrm{~nm} \mathrm{Au}$ NPs. Comparing Figure 8(a) with Figure 8(c), when the distance between nanorods was close enough, the electric field enhanced for Au-NPs on different nanorods would occur. Through simulation, when the diameter of Au-NPs and gap between $\mathrm{TiO}_{x}-\mathrm{NRs}$ are $40 \mathrm{~nm}$ and $100 \mathrm{~nm}$, respectively, there would be the highest surface electric field enhancement. The distribution of $\mathrm{Au}-\mathrm{NPs}$ and $\mathrm{TiO}_{x}-\mathrm{NRs}$ in experiment was not as uniform as the simulation model, but the simulation can reveal the tendency.

After that, the Raman spectra of SERS substrates dyed by R6G with concentration ranging from $10^{-6} \mathrm{M}$ to $10^{-11} \mathrm{M}$ are detected, and the results are shown in Figure 9. Sharp Raman signal peaks of R6G (e.g., 1650.6, 1573.7, 1508.5, 1362, 1313, 1186,774 , and $611 \mathrm{~cm}^{-1}$ ) could be still found on the sample dyed by $10^{-10} \mathrm{M}$ R6G. The peak location in the spectra was about $2 \mathrm{~cm}^{-1}$ shift compared with Peter Hildebrandt's work [42]. Both R6G chemical absorption on Au-NP and R6G interaction with semiconductor substrate could cause Raman shift $[17,43]$.

The enhancement factor of $10^{-6} \mathrm{M}$ and $10^{-10} \mathrm{M}$ R6G on the substrates was calculated by using the formula $\mathrm{EF}_{\mathrm{SERS}}=\left[\left(I_{\mathrm{SERS}} / C_{\mathrm{SERS}}\right) /\left(I_{\mathrm{Ref}} / C_{\mathrm{Ref}}\right)\right][44]$, respectively, where

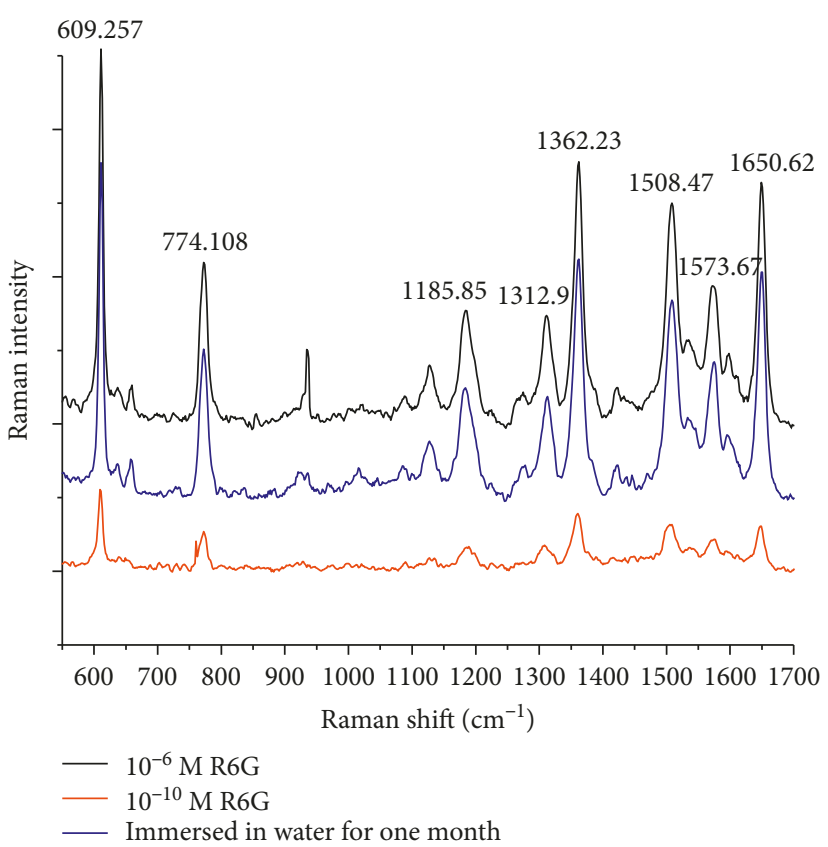

FIgURE 9: The Raman spectra for the substrates dyed by different concentrations of R6G. And the Raman signal of sample immersed in water for one month which was dyed by $10^{-6} \mathrm{M}$ R6G.

$I_{\text {SERS }}$ is the Raman signal intensity of R6G on our SERS substrate, $I_{\text {Ref }}$ is the Raman signal intensity of R6G on the $\mathrm{TiO}_{x}$-NRs array without $\mathrm{Au}-\mathrm{NPs}$, and $\mathrm{C}$ represents $\mathrm{R} 6 \mathrm{G}$ concentration. The Raman signal intensity of $10^{-1} \mathrm{M}$ R6G was chosen as the reference group. The Raman intensity at peak $1650.62 \mathrm{~cm}^{-1}$ was chosen to calculate. The Raman enhancement factors of $10^{-6} \mathrm{M}$ and $10^{-10} \mathrm{M}$ R6G were calculated as $6.65 \times 10^{5}$ and $2.64 \times 10^{8}$, respectively.

From Figure 9, it could be found that the Raman enhancement of the substrate is hardly weakened even after immersed in water for one month. The relative standard deviation (RSD) of all main Raman peaks of R6G on the substrate was calculated by detecting ten different points randomly on the same sample. The values are ranging from $10.4 \%$ to $16.7 \%$. As stated above, it suggests that this SERS substrate is effective, stable, and uniform.

\section{Conclusions}

A novel SERS substrate based on semiconductor $\mathrm{TiO}_{x}$-NRs decorated with Au-NPs on FTO glass was prepared by hydrothermal synthesis and citrate reduction.

For the hydrothermal synthesis of $\mathrm{TiO}_{x}$-NRs, higher $\mathrm{HCl}$ concentration and $\mathrm{NaCl}$ concentration could result in the looser and smaller $\mathrm{TiO}_{x}$-NRs. Our substrate material is $\mathrm{TiO}_{1.04}$ rather than $\mathrm{TiO}_{2} . \mathrm{TiO}_{1.04}$ with charge transfer mechanism could perform better than $\mathrm{TiO}_{2}$ in the SERS detection. Compared with sputtering Au-NPs, those formed by citrate reduction shows better distribution uniformity and sidewall attaching ability.

$\mathrm{TiO}_{x}$-NRs with the diameter from $150 \mathrm{~nm}$ to $200 \mathrm{~nm}, \mathrm{Au}$ NPs with the diameter $40 \mathrm{~nm}$, and $5 \sim 10 \mathrm{~nm}$ nanogaps between $\mathrm{Au}-\mathrm{NPs}$ show the highest Raman sensitivity. For this 
kind of SERS substrate, the detection limit of R6G reaches $10^{-10} \mathrm{M}$, and the enhancement factor is about $2.64 \times 10^{8}$. Meanwhile, the Raman signal on the substrate shows good area uniformity and long-time stability.

In summary, this kind of $\mathrm{TiO}_{x}$-NRs SERS substrate decorated with uniform Au-NPs shows high sensitivity and has great application potential in trace-level organic molecule detection.

\section{Conflicts of Interest}

The authors declare that they have no conflicts of interest.

\section{Acknowledgments}

The authors gratefully acknowledge the financial support from the National High-Tech R\&D Program of China (2012AA02A104).

\section{References}

[1] M. D. Porter, R. J. Lipert, L. M. Siperko, G. Wang, and R. Narayanan, "SERS as a bioassay platform: fundamentals, design, and applications," Chemical Society Reviews, vol. 37, no. 5, pp. 1001-1011, 2008.

[2] X. Li, G. Chen, L. Yang, Z. Jin, and J. Liu, "Multifunctional Au-coated $\mathrm{TiO}_{2}$ nanotube arrays as recyclable SERS substrates for multifold organic pollutants detection," Advanced Functional Materials, vol. 20, no. 17, pp. 2815-2824, 2010.

[3] H. Ilkhani, T. Hughes, J. Li, C. J. Zhong, and M. Hepel, "Nanostructured SERS-electrochemical biosensors for testing of anticancer drug interactions with DNA," Biosensors and Bioelectronics, vol. 80, pp. 257-264, 2016.

[4] A. Radzol, K. Y. Lee, W. Mansor, and N. Othman, "Principal component analysis for detection of NS1 molecules from Raman spectra of saliva," in Proceedings of IEEE 11th International Colloquium on Signal Processing \& Its Applications (CSPA), pp. 168-173, Kuala Lumpur, Malaysia, March 2015.

[5] X. Jiang, L. Zhang, T. Wang, and Q. Wan, "High surfaceenhanced Raman scattering activity from Au-decorated individual and branched tin oxide nanowires," Journal of Applied Physics, vol. 106, p. 104316, 2009.

[6] Y. F. Chan, H. J. Xu, L. Cao, Y. Tang, D. Y. Li, and X. M. Sun, " $\mathrm{ZnO} / \mathrm{Si}$ arrays decorated by $\mathrm{Au}$ nanoparticles for surfaceenhanced Raman scattering study," Journal of Applied Physics, vol. 111, no. 3, p. 033104, 2012.

[7] K.-Y. Wu, X.-L. Cheng, and L. P. Lee, "Intra-particle coupling and plasmon tuning of multilayer $\mathrm{Au} /$ dielectric/Au nanocrescents adhered to a dielectric cylinder," Nanotechnology, vol. 23, no. 5, p. 055201, 2012.

[8] I. Alessandri, M. Ferroni, and L. E. Depero, "In situ plasmonheating-induced generation of $\mathrm{Au} / \mathrm{TiO}_{2}$ "hot spots" on colloidal crystals," Chemphyschem: a European Journal of Chemical Physics and Physical Chemistry, vol. 10, no. 7, pp. 1017-1022, 2009.

[9] C.-Y. Deng, G.-L. Zhang, B. Zou et al., “ $\mathrm{TiO}_{2} / \mathrm{Ag}$ composite nanowires for a recyclable surface enhanced Raman scattering substrate," Chinese Physics B, vol. 22, no. 10, p. 106102, 2013.

[10] S. Siddhanta, V. Thakur, C. Narayana, and S. M. Shivaprasad, "Universal metal-semiconductor hybrid nanostructured SERS substrate for biosensing," ACS Applied Materials \& Interfaces, vol. 4, no. 11, pp. 5807-5812, 2012.
[11] G. Sinha, L. E. Depero, and I. Alessandri, "Recyclable SERS substrates based on Au-coated $\mathrm{ZnO}$ nanorods," ACS applied Materials \& Interfaces, vol. 3, no. 7, pp. 2557-2563, 2011.

[12] A. Esmaielzadeh Kandjani, Y. M. Sabri, M. Mohammad-Taheri, V. Bansal, and S. K. Bhargava, "Detect, remove and reuse: a new paradigm in sensing and removal of $\mathrm{Hg}$ (II) from wastewater via SERS-active $\mathrm{ZnO} / \mathrm{Ag}$ nanoarrays," Environmental Science \& Technology, vol. 49, no. 3, pp. 1578-1584, 2015.

[13] Y. Q. Wang, S. Ma, Q. Q. Yang, and X. J. Li, "Size-dependent SERS detection of R6G by silver nanoparticles immersionplated on silicon nanoporous pillar array," Applied Surface Science, vol. 258, no. 15, pp. 5881-5885, 2012.

[14] R. J. Brown, J. Wang, R. Tantra, R. E. Yardley, and M. J. Milton, "Electromagnetic modelling of Raman enhancement from nanoscale substrates: a route to estimation of the magnitude of the chemical enhancement mechanism in SERS," Faraday Discussions, vol. 132, pp. 201-213, 2006.

[15] M. Stockman, "Electromagnetic theory of SERS," in SurfaceEnhanced Raman Scattering, pp. 47-65, Springer, Berlin, Germany, 2006.

[16] X. Wang, W. Shi, G. She, and L. Mu, "Surface-enhanced Raman scattering (SERS) on transition metal and semiconductor nanostructures," Physical Chemistry Chemical Physics, vol. 14, no. 17, pp. 5891-5901, 2012.

[17] L. Yang, X. Jiang, W. Ruan, B. Zhao, W. Xu, and J. R. Lombardi, "Observation of enhanced Raman scattering for molecules adsorbed on $\mathrm{TiO}_{2}$ nanoparticles: chargetransfer contribution," Journal of Physical Chemistry C, vol. 112, no. 50, pp. 20095-20098, 2008.

[18] G. Liu, L. Li, Y. Chen, K. Huang, L. Gong, and F. Tang, "Influence of experimental parameters on the surfaceenhanced Raman scattering via gold nanoparticle arrays," in Proceedings of Symposium on Photonics and Optoelectronics, pp. 1-3, Kunming, China, August 2012.

[19] J. Xie, Q. Zhang, J. Y. Lee, and D. I. C. Wang, "The synthesis of SERS-active gold nanoflower tags for in vivo applications," ACS Nano, vol. 2, no. 12, pp. 2473-2480, 2008.

[20] T. L. Guo, J. G. Li, X. Sun, and Y. Sakka, "Improved galvanic replacement growth of $\mathrm{Ag}$ microstructures on $\mathrm{Cu}$ micro-grid for enhanced SERS detection of organic molecules," Materials Science and Engineering C, vol. 61, pp. 97-104, 2016.

[21] H. Ko, S. Singamaneni, and V. V. Tsukruk, "Nanostructured surfaces and assemblies as SERS media," Small, vol. 4, no. 10, pp. 1576-1599, 2008.

[22] S.-G. Park, H. Hwang, and S.-M. Yang, "Fabrication of highly uniform three-dimensional SERS substrates by control of wettability," Journal of Materials Chemistry C, vol. 1, no. 3, pp. 426-431, 2013.

[23] S. Deng, H. Fan, X. Zhang et al., "An effective surfaceenhanced Raman scattering template based on a Ag nanocluster-ZnO nanowire array," Nanotechnology, vol. 20, no. 17, p. 175705, 2009.

[24] X. Li, H. Hu, D. Li et al., "Ordered array of gold semishells on $\mathrm{TiO}_{2}$ spheres: an ultrasensitive and recyclable SERS substrate," ACS Applied Materials \& Interfaces, vol. 4, no. 4, pp. 21802185, 2012.

[25] T. Wang, Z. Zhang, F. Liao et al., "The effect of dielectric constants on noble metal/semiconductor SERS enhancement: FDTD simulation and experiment validation of $\mathrm{Ag} / \mathrm{Ge}$ and Ag/Si substrates," Scientific Reports, vol. 4, no. 1, p. 4052, 2014.

[26] G. Wu, J. Wang, D. F. Thomas, and A. Chen, "Synthesis of F-doped flower-like $\mathrm{TiO}_{2}$ nanostructures with high photoelectrochemical activity," Langmuir, vol. 24, no. 7, pp. 35033509, 2008. 
[27] H. Gerischer, "On the stability of semiconductor electrodes against photodecomposition," Journal of Electroanalytical Chemistry and Interfacial Electrochemistry, vol. 82, no. 1-2, pp. 133-143, 1977.

[28] Y. Ding and Z. L. Wang, "Structure analysis of nanowires and nanobelts by transmission electron microscopy," Journal of Physical Chemistry B, vol. 108, no. 33, pp. 12280-12291, 2004.

[29] D. L. Morgan, H.-Y. Zhu, R. L. Frost, and E. R. Waclawik, "Determination of a morphological phase diagram of titania/titanate nanostructures from alkaline hydrothermal treatment of Degussa P25," Chemistry of Materials, vol. 20, no. 12 , pp. $3800-3802,2008$.

[30] J. M. Macak, L. V. Taveira, H. Tsuchiya, K. Sirotna, J. Macak, and P. Schmuki, "Influence of different fluoride containing electrolytes on the formation of self-organized titania nanotubes by $\mathrm{Ti}$ anodization," Journal of Electroceramics, vol. 16, no. 1, pp. 29-34, 2006.

[31] Y. Liu, J. Goebl, and Y. Yin, "Templated synthesis of nanostructured materials," Chemical Society Reviews, vol. 42, no. 7, pp. 2610-2653, 2013.

[32] B. Liu and E. S. Aydil, "Growth of oriented single-crystalline rutile $\mathrm{TiO}_{2}$ nanorods on transparent conducting substrates for dye-sensitized solar cells," Journal of the American Chemical Society, vol. 131, no. 11, pp. 3985-3990, 2009.

[33] S. S. Dasary, A. K. Singh, D. Senapati, H. Yu, and P. C. Ray, "Gold nanoparticle based label-free SERS probe for ultrasensitive and selective detection of trinitrotoluene," Journal of the American Chemical Society, vol. 131, no. 38, pp. 1380613812, 2009.

[34] C. T. Nguyen, J. T. Nguyen, S. Rutledge, J. Zhang, C. Wang, and G. C. Walker, "Detection of chronic lymphocytic leukemia cell surface markers using surface enhanced Raman scattering gold nanoparticles," Cancer Letters, vol. 292, no. 1, pp. 91-97, 2010.

[35] S. Shanmukh, L. Jones, J. Driskell, Y. Zhao, R. Dluhy, and R. A. Tripp, "Rapid and sensitive detection of respiratory virus molecular signatures using a silver nanorod array SERS substrate," Nano Letters, vol. 6, no. 11, pp. 2630-2636, 2006.

[36] Y. Zeng, H.-J. Tan, X.-L. Cheng, R. Chen, and Y. Wang, "A highly sensitive biological detection substrate based on $\mathrm{TiO}_{2}$ nanowires supporting gold nanoparticles," in Proceedings of the Optical Sensors and Biophotonics III, pp. 1-7, Shanghai, China, November 2011.

[37] Z. Sun, J. H. Kim, Y. Zhao et al., "Rational design of 3D dendritic $\mathrm{TiO}_{2}$ nanostructures with favorable architectures," Journal of the American Chemical Society, vol. 133, no. 48, pp. 19314-19317, 2011.

[38] A. Pottier, C. Chanéac, E. Tronc, L. Mazerolles, and J.-P. Jolivet, "Synthesis of brookite $\mathrm{TiO}_{2}$ nanoparticles by thermolysis of $\mathrm{TiCl}_{4}$ in strongly acidic aqueous media," Journal of Materials Chemistry, vol. 11, no. 4, pp. 1116-1121, 2001.

[39] H. Gruber and E. Krautz, "Magnetoresistance and conductivity in the binary system titanium-oxygen. I. Titanium oxides with metallic conductivity," Physica Status Solidi (A), vol. 69, pp. 287-295, 1982.

[40] N. F. Mott and L. Friedman, "Metal-insulator transitions in $\mathrm{VO}_{2}, \mathrm{Ti}_{2} \mathrm{O}_{3}$ and $\mathrm{Ti}_{2-x} \mathrm{~V}_{x} \mathrm{O}_{3}$," Philosophical Magazine: A Journal of Theoretical Experimental and Applied Physics, vol. 30, no. 2, pp. 389-402, 2006.

[41] X. Ji, X. Song, J. Li, Y. Bai, W. Yang, and X. Peng, "Size control of gold nanocrystals in citrate reduction: the third role of citrate," Journal of the American Chemical Society, vol. 129, no. 45, pp. 13939-13948, 2007.
[42] P. Hildebrandt and M. Stockburger, "Surface-enhanced resonance Raman spectroscopy of Rhodamine 6G adsorbed on colloidal silver," Journal of Physical Chemistry, vol. 88, no. 24, pp. 5935-5944, 1984.

[43] A. Otto, I. Mrozek, H. Grabhorn, and W. Akemann, "Surfaceenhanced Raman scattering," Journal of Physics: Condensed Matter, vol. 4, no. 5, pp. 1143-1212, 1992.

[44] X. Yang, H. Zhong, Y. Zhu, J. Shen, and C. Li, "Ultrasensitive and recyclable SERS substrate based on Au-decorated Si nanowire arrays," Dalton Transactions, vol. 42, pp. 1432414330, 2013. 


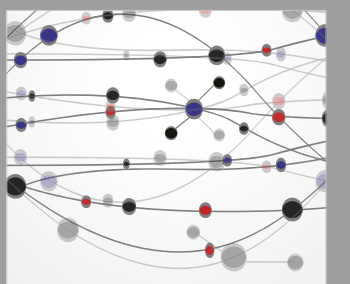

The Scientific World Journal
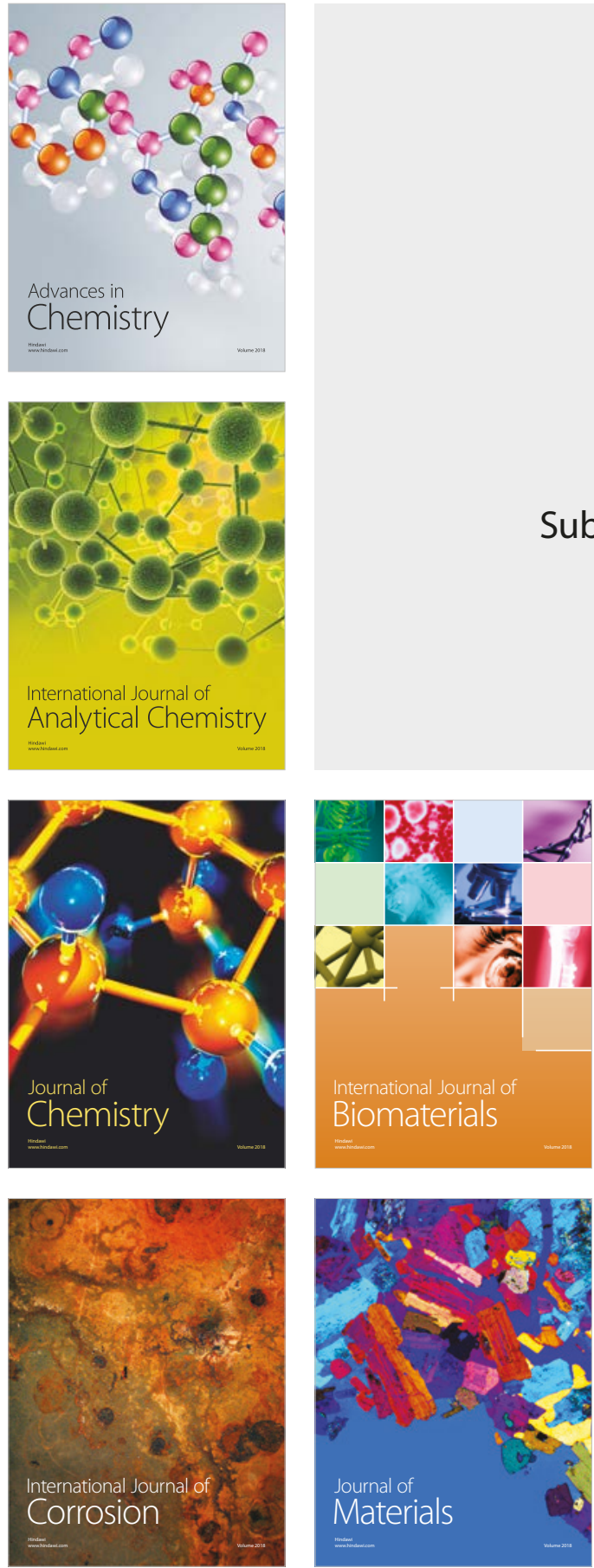

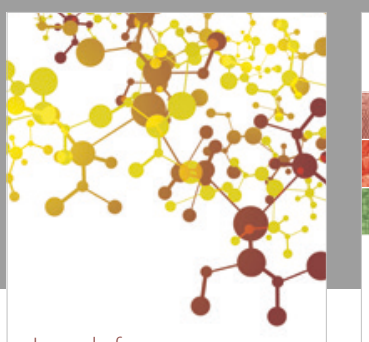

Journal of

Applied Chemistry
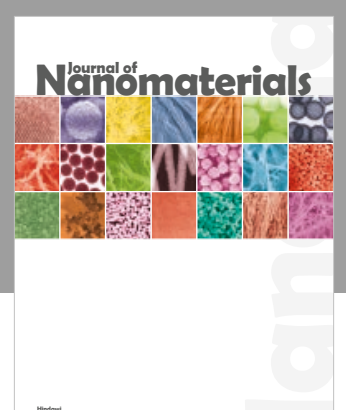

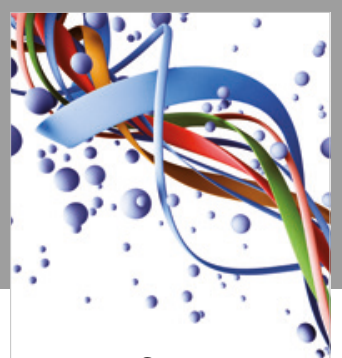

Scientifica

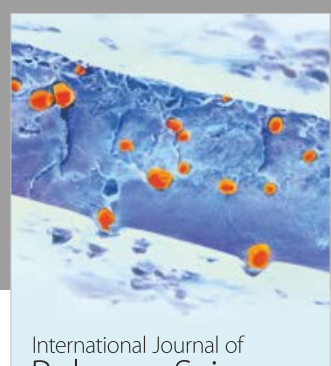

Polymer Science

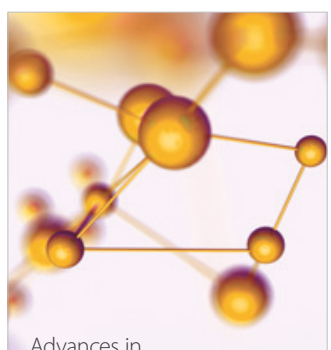

Physical Chemistry
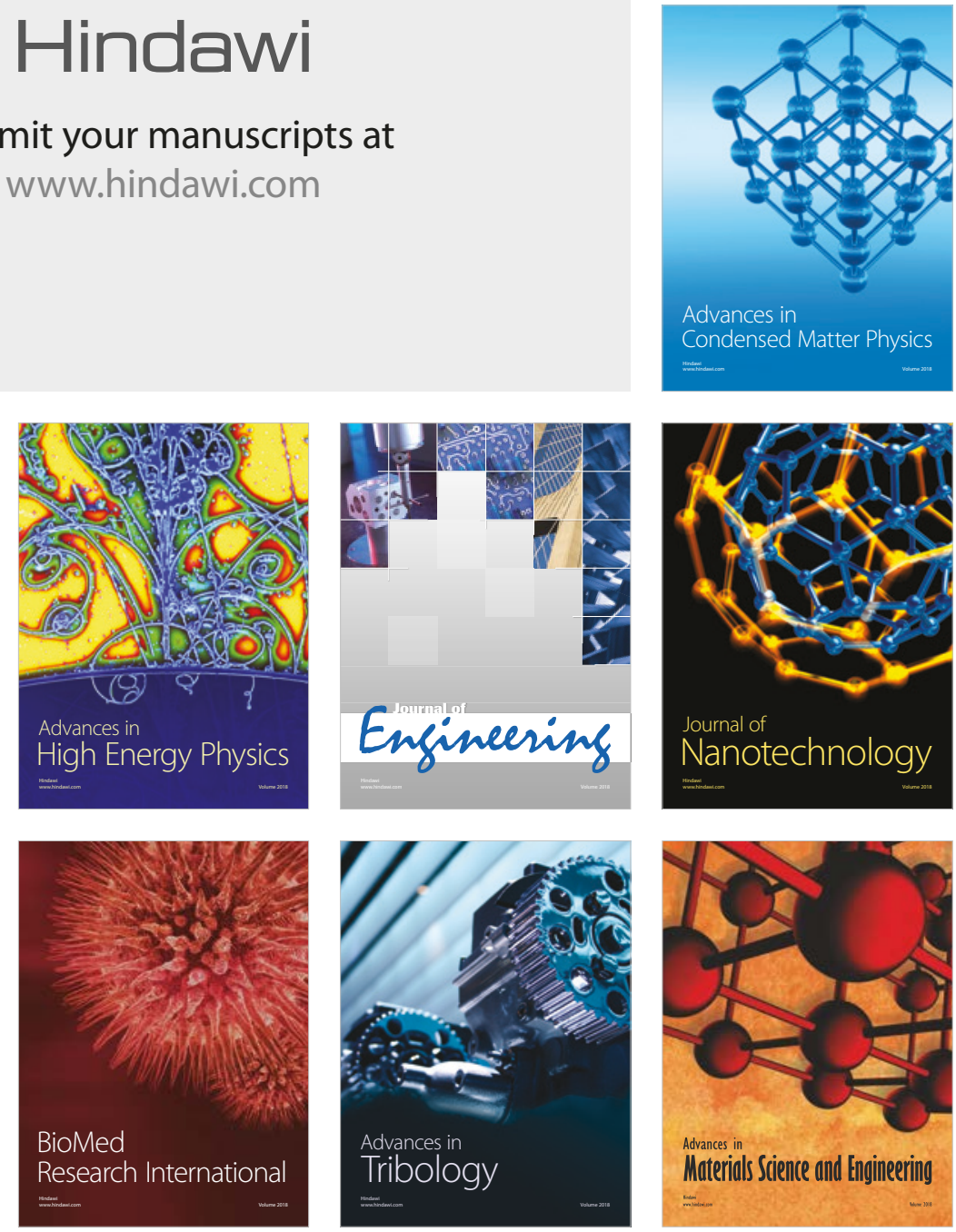